\title{
UTILIZAÇÃO DE FERRAMENTAS DE INTELIGÊNCIA COMPETITIVA PARA DELINEAR ESTRATÉGIAS DE POSICIONAMENTO DE MERCADO DE EQUIPAMENTOS ELETROMÉDICOS DE MONITORAMENTO
}

\author{
Janaina dos Santos Melo할 Maria Fernanda Mascarenhas dos Santos Melis ${ }^{2}$; Levi Santos ${ }^{3}$; Sandra \\ Malveira $^{4}$; Grace Ferreira Ghesti ${ }^{5 *}$; Paulo Gustavo Barboni Dantas Nascimento ${ }^{6}$ \\ 1, 2,3,4,5,6 Programa de Pós Graduação em Propriedade Intelectual e Transferência de Tecnologia para a Inovação - ponto \\ focal UnB -PROFNIT, Brasília, DF, Brasil.
}

Rec.:14/07/2017. Ace.:24/03/2018

\section{RESUMO}

O avanço tecnológico propiciou o desenvolvimento de equipamentos eletromédicos de monitoramento de altíssima complexidade e sofisticação. Tais equipamentos realizam o monitoramento de outros equipamentos eletromédicos a fim antecipar ou alertar irregularidades, possibilitando a redução de custo com adequada manutenção preventiva e reparo. Nesse sentido, o presente trabalho objetivou traçar estratégias de posicionamento de um equipamento eletromédico no mercado, por meio de prospecções científica, tecnológica e mercadológica, bem como pela utilização de outras ferramentas de inteligência competitiva. As prospecções, realizadas por meio de buscas em bases de patentes e em bases de periódicos embasaram a análise e aplicação das modalidades de contrato e custeio para transferência de tecnologia. De modo geral, os dados obtidos demonstraram um grande potencial mercadológico o qual acarreta uma transação facilitada da transferência de tecnologia.

Palavras-chave: Prospecção. Competitiva. Transferência.

\section{USE OF COMPETITIVE INTELLIGENCE TOOLS TO DELINE MARKET POSITIONING STRATEGIES FOR ELECTRONIC MONITORING EQUIPMENT}

\begin{abstract}
The technological advance led to the development of electro medical monitoring equipment of extremely high complexity and sophistication. Such equipment carries out the monitoring of other electro medical equipment in order to anticipate or alert irregularities, enabling cost reduction with adequate preventive maintenance and repair. In this sense, the present work aimed to outline strategies for positioning an electro medical equipment in the market, through scientific, technological and marketing prospecting, as well as the use of other competitive intelligence tools. The surveys carried out through searches in patent bases and in periodical bases, supported the analysis and application of contract modalities and costing for technology transfer. In general, the data obtained showed a great marketing potential which entails a facilitated transaction of technology transfer.
\end{abstract}

Keywords: Prospection. Competitive. Technology.

Área tecnológica: Ciências da Saúde. Engenharia Clínica. Propriedade Intelectual.

* Autor para correspondência: ghesti.grace@gmail.com 


\section{INTRODUÇÃO}

O avanço tecnológico ocasionou uma disruptura no que concerne a automatização dos equipamentos e procedimentos médicos no setor da saúde propiciando uma maior precisão, rapidez e minimização dos custos.

Segundo definição da Associação Brasileira de Normas Técnicas (ABNT), equipamentos eletromédicos (EEM) são equipamentos dotados de conexão com rede de alimentação elétrica que têm por finalidade diagnosticar, tratar ou monitorar paciente, sob supervisão médica (ASSOCIAÇÃO BRASILEIRA DE NORMAS TÉCNICAS, 1994; 1997).

Esses equipamentos têm um alto custo de investimento e "para que o grande volume de investimentos realizados na instalação desses equipamentos maximize a utilidade dos recursos públicos alocados é necessário que haja um programa de manutenção adequado, capaz de ampliar a vida útil dos equipamentos" (MINISTÉRIO DA SAÚDE, 2002 apud NASCIMENTO; TANAKA, 2014).

Segundo relatório da Associação Nacional dos Hospitais Privados (ANAHP), as despesas com manutenção e assistência técnica foram as que mais cresceram entre os anos de 2013 e 2014, chegando a um aumento de 15,6\% (XAVIER, 2015).

Esta realidade também é vista no Sistema Único de Saúde (SUS). Em relatório preliminar do TCDF, de auditoria realizada entre outubro de 2015 e março de 2017, em unidades de saúde da rede pública do Distrito Federal, constatou que apenas $20 \%$ dos equipamentos médicos utilizados predominantemente em unidades de terapia intensiva da Secretaria de Estado de Saúde do Distrito Federal - SESDF possuem cobertura contratual para manutenção preventiva e corretiva (DISTRITO FEDERAL, 2017).

De janeiro a maio de 2015 a SESDF gastou mais de R\$ 63.000.000,00 com a manutenção de máquinas e equipamentos. O previsto para esta rubrica, para todo o ano de 2015 , de acordo com a Lei Orçamentária Anual (LOA), era de R\$ 50.938.000,00. Ou seja, o gasto com equipamentos médicos foi cerca de $24 \%$ maior que o previsto (DISTRITO FEDERAL, 2015).

Tomando por base este cenário de elevado custo com manutenção hospitalar, o Ministério da Saúde financiou projetos de pesquisas com vista ao desenvolvimento de um equipamento eletromédico capaz de monitorar outros equipamentos médicos e reduzir esse tipo de gasto.

Os EEM têm por finalidade monitorar o desempenho e coletar dados de outros equipamentos eletromédicos, a fim de evitar que estes fiquem sem utilização por falta de manutenção, por problemas simples ou por utilização inadequada. A comunicação dessas tecnologias com outros equipamentos possibilita a coleta imagens, dados, informações, que são armazenados em memória interna. Periodicamente, as informações coletadas são enviadas para um ambiente em nuvem a fim de se evitar a sobrecarga e a queda de desempenho das próprias tecnologias.

Pautando-se na importância dessa tecnologia, que é uma potencial ferramenta de gestão hospitalar, este trabalho teve por objetivo utilizar ferramentas de inteligência competitiva a fim de posicionálas no mercado de Equipamentos Médicos, Hospitalares e Odontológicos (EMHO).

A inteligência competitiva é um processo de análise do ambiente interno e externo de uma empresa. As informações obtidas por meio destas análises são utilizadas de forma estratégica. Ou seja, a inteligência competitiva tem por objetivo "acompanhar as tendências do mercado, verificando se as estratégias estão aproveitando as oportunidades e as fortalezas, sem ignorar as ameaças e os pontos fracos" (SEBRAE, 2017c). Segundo Borschiver e Silva a inteligência competitiva

MELO, J. dos S. et al..Utilização de ferramentas de inteligência competitiva para delinear estratégias de posicionamento de mercado de equipamentos eletromédicos de monitoramento. 
[...] não visa somente analisar as condições de mercado ou do seu concorrente, mas sim avaliar o desempenho dos seus concorrentes dentro deste[s] ambiente[s] e produzir informações que consigam fazer com que sua empresa supere-os, mesmo que as condições de mercado estejam igualitárias (BORSCHIVER; SILVA, 2016, p. 24).

Gomes e Braga (2011) defendem que a inteligência competitiva assume um papel estratégico de obtenção de conhecimento contínuo e preciso do ambiente no qual a empresa encontra-se inserida e que é composto de variáveis de natureza política, social, econômica e tecnológica.

\section{METODOLOGIA}

Este trabalho caracterizou-se por sua natureza exploratória descritiva com abordagem qualiquantitativa.

A fim de otimizar o processo de inteligência competitiva voltado ao mercado de equipamentos médicos, hospitalares e odontológicos foram utilizadas as seguintes ferramentas e métodos de análise: Prospecções científica, tecnológica e mercadológica; Matriz SWOT; Forças Competitivas de Porter; e Technology Readiness Levels (TRL).

Para subsidiar a utilização das ferramentas matriz SWOT, Forças de Porter e TRL foram recuperados 1.155 artigos, 550 patentes sobre equipamentos eletromédicos de monitoramento e dados de empresas e fabricantes nacionais e internacionais de EMHO.

Foram utilizadas as bases de dados da Biblioteca Virtual em Saúde (BVS) e da Web of Science, para a prospecção científica e as bases de bancos de patentes Espacenet e Patentscope para a prospecção tecnológica. Para a prospecção mercadológica foi utilizada a base MarketLine em conjunto com estudo prospectivo da Agência Brasileira de Desenvolvimento Industrial (ABDI).

Para a escolha dos termos foi utilizado o vocabulário estruturado e trilíngue chamado Descritores em Ciências da Saúde (DeCS), criado pela Biblioteca Regional de Medicina (BIREME) e disponível na BVS.

A pesquisa, realizada entre os meses de abril e junho de 2017, utilizou as seguintes estruturas de busca:

Quadro 1 - Estruturas de busca utilizadas nas prospecções.

\begin{tabular}{|c|c|}
\hline \multirow[t]{2}{*}{ Prospecção científica } & ("equipment and supplies" OR "equipment maintenance") AND monitoring \\
\hline & "medical device" AND "preventive maintenance" AND monitoring \\
\hline \multirow[t]{5}{*}{ Prospecção tecnológica } & ("medical device" AND "preventive maintenance" AND monitoring) \\
\hline & ("medical equipment monitoring device" \\
\hline & "medical equipment monitor" OR "medical equipment monitoring" \\
\hline & "medical equipment monitor" AND "operating conditions" \\
\hline & "monitoring system” AND “medical devices \\
\hline \multirow[t]{2}{*}{ Prospecção mercadológica } & monitoring equipment \\
\hline & electromedical equipment \\
\hline
\end{tabular}

MELO, J. dos S. et al..Utilização de ferramentas de inteligência competitiva para delinear estratégias de posicionamento de mercado de equipamentos eletromédicos de monitoramento. 
Fonte: Autoria própria.

Em seguida foi realizada triagem dos dados, tendo como critérios de exclusão: a) resultados duplicados; b) patentes e/ou artigos que fugissem à temática de equipamentos eletromédicos de monitoramento.

\section{RESULTADOS E DISCUSSÃO}

A fim de avaliar os EEM e sua inclusão no mercado e rotina médica odontológica, o presente trabalho realizou três tipos de prospecção para embasar a utilização das demais ferramentas de inteligência competitiva, as quais foram: a tecnológica, por meio da pesquisa de patentes; a científica, com a pesquisa de artigos correlatos à temática "equipamentos eletromédicos de monitoramento"; e a mercadológica, na qual buscou-se empresas fabricantes e comerciantes que compõem o mercado de EMHO.

De acordo com Borschiver e Silva os resultados das prospecções devem ser analisados com cautela, uma vez que envolvem variáveis socioeconômicas, políticas, culturais e tecnológicas num período de tempo longo. Por isso, as decisões tomadas com base nas prospecções devem ser flexíveis para mudanças pelo fato de que "devem levar em conta a dinâmica dos fatores externos e o grau de influência que estes possam ter em relação à organização ou sistema estudado" (BORSCHIVER; SILVA, 2016, p. 29).

As prospecções científica e tecnológica mostraram que artigos sobre equipamentos eletromédicos de monitoramento começaram a ser publicados a partir do ano de 1960, enquanto as primeiras patentes apareceram somente em 1980. Observou-se, por meio do Gráfico 1, que, a partir do ano de 2011, houve um movimento de ziguezague na publicação de artigos, no qual os anos pares foram de crescimento e os anos ímpares de queda na quantidade de publicações. O pico de publicações ocorreu nos anos de 2014 e 2016.

Gráfico 1 - Evolução anual dos artigos e patentes.

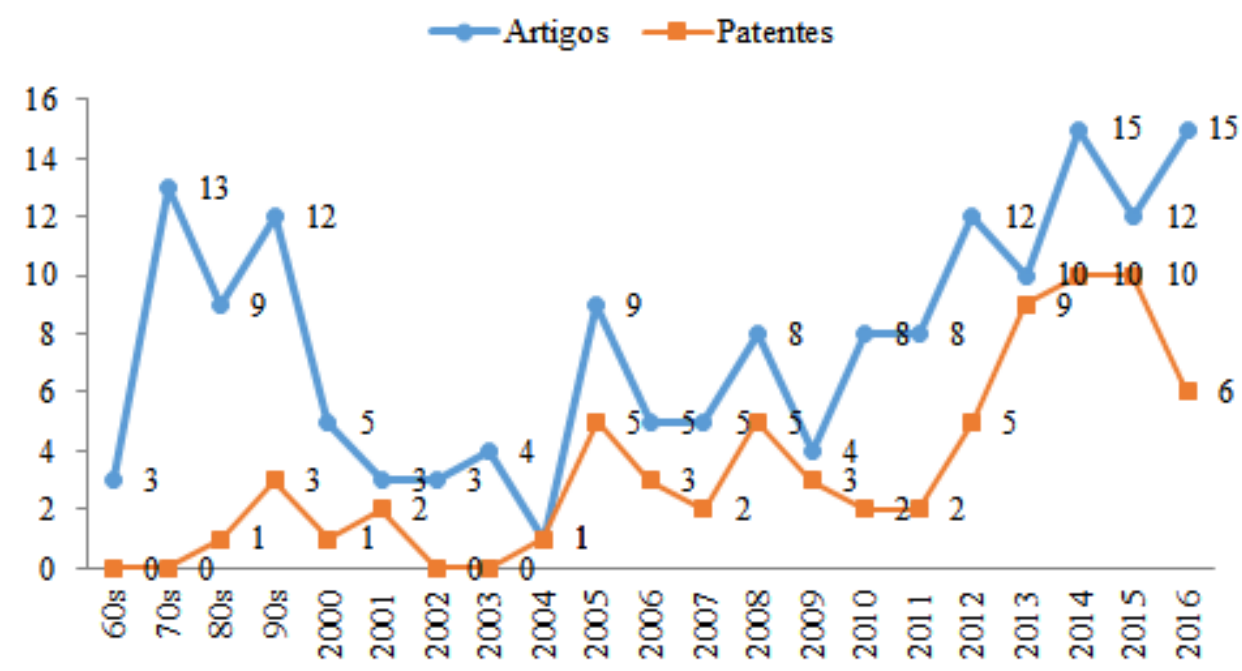

Fonte: Autoria própria.

Também foi possível analisar, por meio da prospecção científica e tecnológica que as pesquisas na MELO, J. dos S. et al..Utilização de ferramentas de inteligência competitiva para delinear estratégias de posicionamento de mercado de equipamentos eletromédicos de monitoramento. 
área de equipamentos eletromédicos de monitoramento cresceram nos últimos anos, mesmo com oscilações nas quantidades de artigos publicados e patentes depositadas. Ou seja, a tecnologia de equipamentos de monitoramento já se consolidou tanto na fase científica quanto na tecnológica, havendo equilíbrio entre a quantidade de patentes depositadas e artigos publicados.

As prospecções também evidenciaram que os Estados Unidos são a nação que mais publicam sobre equipamentos eletromédicos, conforme demonstrado no gráfico 2. Notou-se que, dentre os artigos selecionados, quase metade foi publicado em revista científica norte-americana. A mesma tendência com relação a patentes foi observada onde os Estados Unidos da América são os que mais depositam, seguido pelo Canadá e Japão, Gráfico 3.

Gráfico 2 - Países que mais publicam artigos científicos.

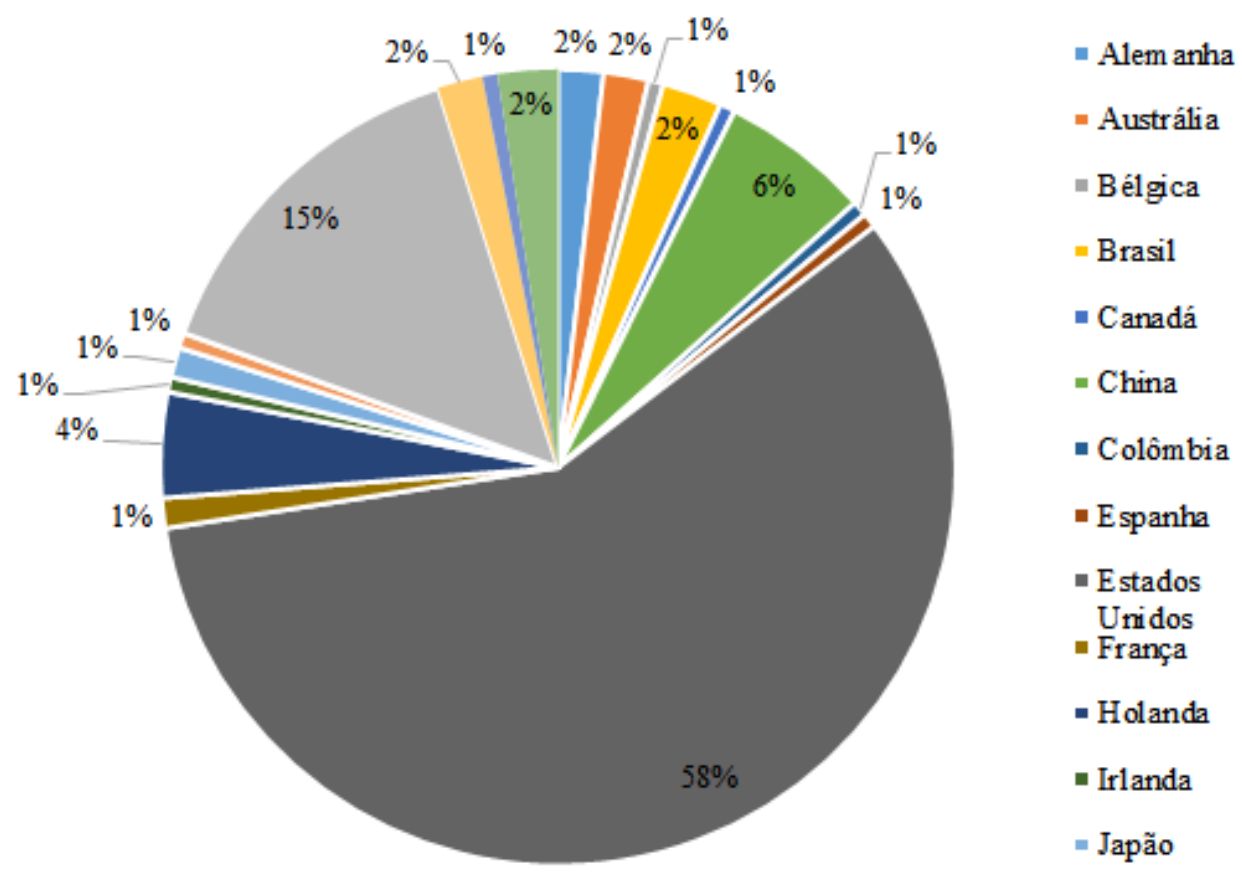

Fonte: Autoria própria.

Gráfico 3 - Origem das patentes.

MELO, J. dos S. et al..Utilização de ferramentas de inteligência competitiva para delinear estratégias de posicionamento de mercado de equipamentos eletromédicos de monitoramento. 


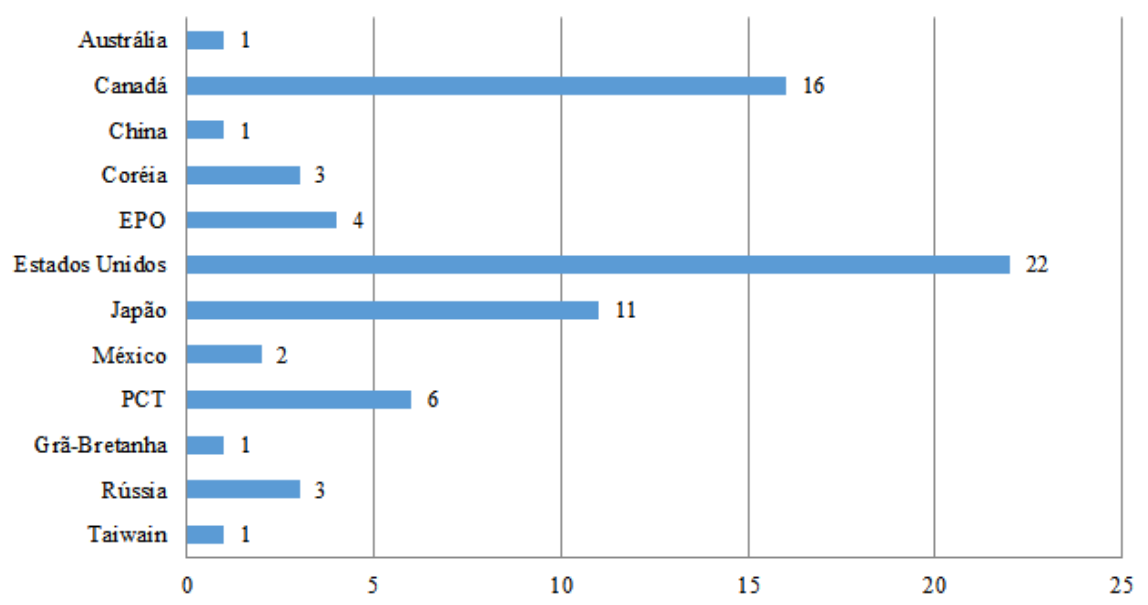

Fonte: Autoria própria.

Visando a análise da quantidade de patentes depositadas na área foi feito um levantamento nos bancos de patentes do Espacenet e Patentscope utilizando somente os números da Classificação Internacional de Patentes - CIP dos grupos ou subgrupos com maior ocorrência na busca de patentes por descritores: A61B5/00 and G06F19/00 and H04L29/08. Na base Espacenet foram recuperadas 111 patentes e na Patentscope 192. Após as devidas exclusões restaram 177 patentes para análise.

No gráfico 4 é possível observar que 134 das patentes recuperadas pela pesquisa por CIP mais recorrentes são da área de saúde, ressaltando que mesmo com a utilização de várias classificações para designar a função ou aplicabilidade de uma patente as CIP mais recuperadas na prospecção, de fato, abrangem a área da pesquisa.

Gráfico 4 - Distribuição do CIP por área do conhecimento

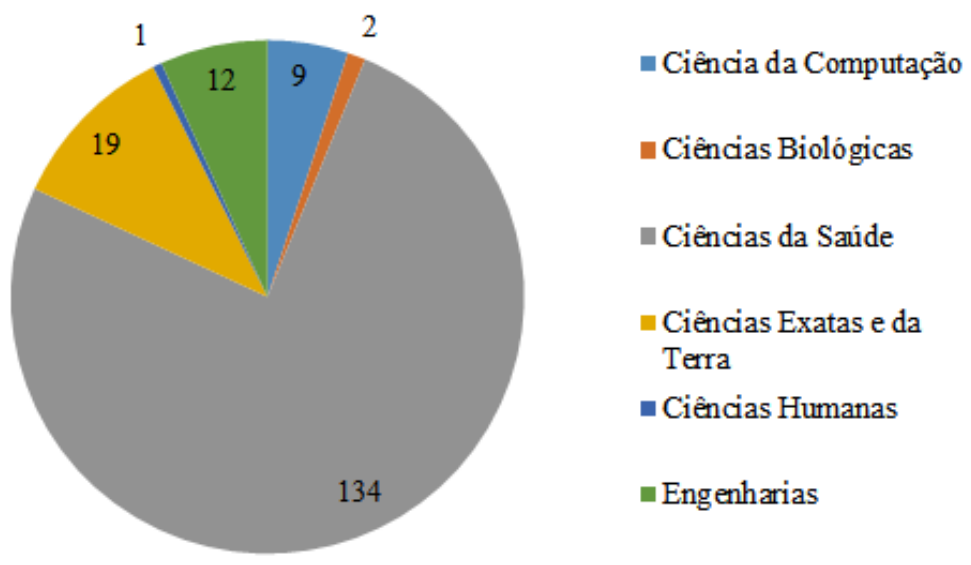

Fonte: Autoria própria.

No que tange à prospecção mercadológica, foi realizada por meio da base MarketLine, na qual detectou-se quatro empresas que comercializam equipamentos eletromédicos, sendo que três delas estão localizadas nos Estados Unidos. De acordo com a Agência Brasileira de Desenvolvimento

MELO, J. dos S. et al..Utilização de ferramentas de inteligência competitiva para delinear estratégias de posicionamento de mercado de equipamentos eletromédicos de monitoramento. 
Industrial (ABDI), os Estados Unidos apresenta constante superávit no setor de equipamentos médico-hospitalares e odontológicos, mesmo com redução das exportações entre os anos de 1999 a 2006 (AGÊNCIA BRASILEIRA DE DESENVOLVIMENTO INDUSTRIAL, 2008a, p. 56).

Já no mercado brasileiro, conforme dados da ABDI (2008b), as principais empresas brasileiras fabricantes de EMHO, localizam-se no Estado de São Paulo.

O governo brasileiro, juntamente com o setor industrial tem incentivado o mercado EMHO por meio de ações políticas.

De acordo com a Agência Brasileira de Desenvolvimento Industrial

\begin{abstract}
[...] é raro encontrar empresas que fabricam exclusivamente equipamentos de monitoração. Normalmente, o foco da empresa é outro, e a linha de produção de monitores complementa o produto principal. Por esse motivo, é difícil obter informações de importação e exportação de Equipamentos de Monitoração a partir das informações oficiais do Ministério de Desenvolvimento, Indústria e Comércio Exterior (MDIC) (AGÊNCIA BRASILEIRA DE DESENVOLVIMENTO INDUSTRIAL, 2008a, p. 103).
\end{abstract}

Segundo os maiores fabricantes de EMHO outro motivo que dificulta o acesso à informações de importação e exportação de equipamentos de monitoramento está na classificação destes equipamentos. A maioria é enquadrada na classificação "outros aparelhos de eletrodiagnóstico", mas parte significativa também é classificada no grupo "outros instrumentos e aparelhos para medicina cirúrgica", no qual, por razões tributárias ou inexistência de classificações específicas, são alocados diversos tipos de equipamentos (AGÊNCIA BRASILEIRA DE DESENVOLVIMENTO INDUSTRIAL, 2008a).

O Panorama setorial de EMHO da ABDI mostra que o mercado mundial concentra-se nos países desenvolvidos, tendo os Estados Unidos na liderança, com participação correspondente a 37\%, seguido por Alemanha, Japão e França. "A competitividade de cada país pode variar conforme o subsetor em que o produto está inserido", mas fato é que os Estados Unidos apresentam superávit frente a maioria dos países (USDOC, 2006 apud AGÊNCIA BRASILEIRA DE DESENVOLVIMENTO INDUSTRIAL, 2008b, p. 50).

No Brasil ocorreu aumento na produção de EMHO e o desenvolvimento de novas tecnologias a partir do final dos anos 90, com a abertura econômica. Há prevalência de pequenas e médias empresas, mas as grandes empresas são responsáveis por quase $70 \%$ do faturamento. A ABDI levantou a existência de cerca de 500 empresas no mercado de EMHO, as quais têm faturamento médio anual de 3,09 bilhões de dólares (AGÊNCIA BRASILEIRA DE DESENVOLVIMENTO INDUSTRIAL, 2008b).

Diante deste cenário, é possível concluir que há mercado nacional e internacional para EEM a serem desenvolvidos em âmbito nacional. Atualmente, segundo a ABIMO existem 4.290 empresas do ramo, que faturaram, em 2015, R\$ 3,57 bilhões (ASSOCIAÇÃO BRASILEIRA DA INDÚSTRIA DE ARTIGOS E EQUIPAMENTOS MÉDICOS, ODONTOLÓGICOS, HOSPITALARES E DE LABORATÓRIOS, 2017a). No acumulado entre janeiro e outubro de 2016, o Brasil exportou US\$ 142,6 milhões para os Estados Unidos e importou o equivalente a US\$ 925,7 milhões também do país norte-americano (ASSOCIAÇÃO BRASILEIRA DA INDÚSTRIA DE ARTIGOS E EQUIPAMENTOS MÉDICOS, ODONTOLÓGICOS, HOSPITALARES E DE LABORATÓRIOS, 2017b).

Após as prospecções foi possível aplicar a Matriz SWOT, quadro 2, quanto a EEM nacionais, que subsidiou a tomada de decisões acerca do posicionamento de mercado dessas tecnologias. Os fatores internos são denominados forças e fraquezas, e os fatores externos são definidos como oportunidades e ameaças.

MELO, J. dos S. et al..Utilização de ferramentas de inteligência competitiva para delinear estratégias de posicionamento de mercado de equipamentos eletromédicos de monitoramento. 
Ao aplicar a Matriz SWOT para essas tecnologias, pode-se considerar que as forças como os recursos ou capacidades que a diferenciam dos demais equipamentos eletromédicos e que podem e devem ser exploradas. As fraquezas são limitações das tecnologias que podem vir a dificultar sua inclusão ou aceitação pelo mercado. As oportunidades são acontecimentos e/ou tendências que podem vir a alavancar a tecnologia analisada. E as ameaças são tendências e/ou situações que podem impactar negativamente a tecnologia e seu posicionamento no mercado.

Quadro 2 - Matriz SWOT.

\begin{tabular}{|c|c|}
\hline FORÇAS & FRAQUEZAS \\
\hline $\begin{array}{l}\text { Tecnologias nacionais; } \\
\text { - } \quad \text { Custo menor que o de equipamentos } \\
\text { semelhantes importados; } \\
\text { - } \quad \text { Possibilita a gestão dos equipamentos } \\
\text { eletromédicos; } \\
\text { - Diminuição no tempo gasto para } \\
\text { manutenção dos equipamentos monitorados; } \\
\text { - } \quad \text { Eficiência nos processos de compras de } \\
\text { um ambiente hospitalar; } \\
\text { - } \quad \text { Redução dos custos de manutenção; } \\
\text { - Tecnologias desenvolvidas em diálogo } \\
\text { com a Universidade e Ministério da Saúde; }\end{array}$ & $\begin{array}{l}\text { - Tecnologias envolvidas com os trâmites } \\
\text { burocráticos da Administração Pública; } \\
\text { - Amplitude na proposta de comunicação } \\
\text { com diversos equipamentos; } \\
\text { - Tecnologias dependente de manutenção } \\
\text { por empresas de assistência técnica e } \\
\text { armazenamento dos dados em nuvem; }\end{array}$ \\
\hline OPORTUNIDADES & AMEAÇAS \\
\hline $\begin{array}{l}\text { - Ausência de uma solução brasileira que } \\
\text { monitore aparelhos médicos possibilitando a } \\
\text { manutenção preventiva; } \\
\text { - Empresas interessadas } \\
\text { Licenciamentos da Tecnologia; } \\
\text { - Apoio do Ministério da Saúde para } \\
\text { testes e consolidação de tecnologias } \\
\text { desenvolvidas em âmbito nacional; }\end{array}$ & $\begin{array}{l}\text { - Pendência da realização de Testes em } \\
\text { seres humanos; } \\
\text { - Possibilidade de tecnologias serem } \\
\text { melhoradas e aplicadas no exterior; } \\
\text { - Fluxo contínuo de modificações nas } \\
\text { portas de equipamentos médicos; } \\
\text { - Dependência de financiamento da } \\
\text { iniciativa pública e ausência de recursos de } \\
\text { outras fontes; } \\
\text { - Inflação médica. }\end{array}$ \\
\hline
\end{tabular}

Fonte: Autoria própria.

Com base nos dados das prospecções foi possível também realizar a análise das forças competitivas de Porter, que é uma ferramenta de análise ambiental a qual auxilia o posicionamento de mercado de tecnologias, desenvolvida por Michael Porter. Para as tecnologias envolvendo EEM pode-se elencar as seguintes forças: a) Entrantes Potenciais: o investimento inicial para o desenvolvimento de um equipamento eletromédico é alto. Existem custos derivados de inovações tecnológicas, demanda por pesquisa contínua e por conhecimento especializado. Além disto, há legislações e diretrizes de órgãos competentes, tais como ANVISA, Instituto Nacional de Metrologia, Qualidade e Tecnologia (INMETRO) e comissões de ética, que regulam o mercado de EEM. Tais fatos podem ser considerados fatores limitantes à entrada de novos concorrentes. $\mathrm{O}$ fato da barreira de entrada no mercado de EMHO ser mais alto diminui a competição feita pelos potenciais entrantes. b) Poder de

MELO, J. dos S. et al..Utilização de ferramentas de inteligência competitiva para delinear estratégias de posicionamento de mercado de equipamentos eletromédicos de monitoramento. 
Barganha dos Compradores: em outras situações o poder de barganha dos compradores pode ser alto, tendo em vista que estes fazem pesquisas de preço e compram de fornecedores que mais dão benefícios. Mas, no caso dessas tecnologias, por não possuir concorrente nacional direto, o poder de barganha dos compradores é diminuído. Contudo, não há como menosprezar este fator, uma vez que muitos estabelecimentos de saúde ainda relutam quanto à implantação de gestão interna de manutenção, o que pode impactar na aquisição de equipamentos. c) Produtos Substitutos: a ameaça de novos produtos substitutos é baixa, tendo em vista o alto investimento para o desenvolvimento de equipamentos. Além disso, o tempo gasto desde a construção até a inclusão do produto no mercado também diminui a possibilidade de surgimento de equipamentos semelhantes. Também há o fato de que poucos estabelecimentos se preocupam em adotar programas de manutenção preventiva. d) Concorrentes: em qualquer segmento a competição existe e a disputa entre concorrentes pode ser uma das forças mais significativas. Isto ocorre devido ao fato desta força não poder ser controlada. O número de empresas do ramo de EMHO é alto, principalmente internamente e as barreiras de saída são altas, como, por exemplo, os ativos especializados.

Por meio dessa ferramenta, verificou-se também que as forças que determinam o potencial lucrativo de uma empresa, com relação às tecnologias estudadas são: a ameaça de novos entrantes; a ameaça de produtos substitutos; o poder de negociação dos compradores; o poder de negociação dos fornecedores e a rivalidade entre os concorrentes existentes.

No que se refere a maturidade de tecnologias EEM, pode ser aferida por meio de ferramenta Technology Readiness Levels (TRL) e, tomando por base os dados das prospecções, a maturação da tecnologia, encontra-se no nível misto como descrito no quadro 3. Ou seja, as tecnologias de equipamentos de monitoramento já se consolidaram tanto na fase científica quanto na tecnológica, havendo equilíbrio entre a quantidade de patentes depositadas e artigos publicados, tendo a tecnologia, agora, sendo desenvolvida em todas as dimensões.

Quadro 3 - Níveis de maturidade tecnológica.

\begin{tabular}{|c|c|c|c|}
\hline $\begin{array}{l}\text { Maturidade } \\
\text { tecnológica }\end{array}$ & $\begin{array}{l}\text { Razão entre } \\
\text { patentes e artigos }\end{array}$ & $\begin{array}{l}\text { Mapa das variações } \\
\text { anuais de patentes versus } \\
\text { artigos }\end{array}$ & $\begin{array}{l}\text { Fornecedores } \\
\text { comerciais }\end{array}$ \\
\hline $\begin{array}{l}\text { Portadora de } \\
\text { futuro }\end{array}$ & $\begin{array}{l}\text { Extremamente } \\
\text { variável }\end{array}$ & $\begin{array}{l}\text { Muito perto do eixo dos } \\
\text { artigos }\end{array}$ & Não existem \\
\hline Embrionária & Variável & $\begin{array}{l}\text { Deslocada para o eixo dos } \\
\text { artigos }\end{array}$ & Não existem \\
\hline $\begin{array}{l}\text { Emergente ou } \\
\text { Em crescimento }\end{array}$ & $10 \%$ a $20 \%$ & $\begin{array}{l}\text { Migrando do eixo dos } \\
\text { artigos para o eixo das } \\
\text { patentes com o aumento dos } \\
\text { anos }\end{array}$ & Existem poucos \\
\hline Madura & $15 \%$ a $30 \%$ & $\begin{array}{l}\text { Deslocada para o eixo das } \\
\text { patentes }\end{array}$ & Existem muitos \\
\hline
\end{tabular}

MELO, J. dos S. et al..Utilização de ferramentas de inteligência competitiva para delinear estratégias de posicionamento de mercado de equipamentos eletromédicos de monitoramento. 


\begin{tabular}{|l|l|l|l|} 
Pós-Madura & $10 \%$ a $20 \%$ & $\begin{array}{l}\text { Deslocada para o eixo das } \\
\text { patentes }\end{array}$ & $\begin{array}{l}\text { Existem muitos a sua } \\
\text { venda pode ser } \\
\text { associada com outros } \\
\text { produtos }\end{array}$ \\
\hline Mista & Variável & Variável & $\begin{array}{l}\text { Existem com vários } \\
\text { tipos de tecnologias }\end{array}$ \\
\hline
\end{tabular}

Fonte: Nascimento (2017).

Para Fernandes (1998) a posição competitiva e da maturidade tecnológica são interligadas e constituem um cenário para que se decida onde a empresa deve investir. Ele também afirma que à medida que se caminha da posição obsoleta para embrionária, os riscos aumentam, dada a incerteza da obtenção de sucesso técnico. Por sua vez, também as inovações revelam maior probabilidade de se realizarem.

No que diz respeito ao grau de maturidade tecnológica foi possível analisar, por meio da prospecção científica e tecnológica que as pesquisas na área de equipamentos eletromédicos de monitoramento cresceram nos últimos anos, mesmo com oscilações nas quantidades de artigos publicados e patentes depositadas. Tomando por base os dados das prospecções e o quadro 3, os equipamentos de monitoramento, com relação ao grau de maturação, se encontra no nível misto. Ou seja, a tecnologia de equipamentos de monitoramento já se consolidou tanto na fase científica quanto na tecnológica, havendo equilíbrio entre a quantidade de patentes depositadas e artigos publicados, tendo a tecnologia, agora, sendo desenvolvida em todas as dimensões.

Após análise de tecnologias equipamentos de monitoramento, quanto a sua maturidade, é importante pensar em uma estratégia para inseri-las no mercado e uma forma seria por meio da transferência de tecnologia.

A transferência de tecnologia pode ser entendida como o conjunto de etapas que descrevem a transferência formal de invenções resultantes das pesquisas científicas realizadas pelas universidades ao setor produtivo (STEVENS; TONEGUZZO; BOSTROM, 2005 apud DIAS; PORTO, 2013). A transferência de tecnologia, "permite que as empresas possam adquirir novos produtos, processos ou tecnologia sem a necessidade de participar dos estágios iniciais, caros e arriscados, de pesquisa e desenvolvimento (P\&D)" (HUNG; TANG, 2008 apud DIAS; PORTO, 2013). Nesse sentido, as universidades desempenham um papel importante, atuando como centros de pesquisa e inovação, que fomenta a geração de conhecimento e contribui para o desenvolvimento econômico. Sendo, na maioria das vezes, o estágio inicial para o desenvolvimento de uma nova tecnologia.

Closs e Ferreira (2012) afirmam que

[...] universidade e empresa estão em um ambiente de dependência mútua, visto que as empresas são detentoras da lógica para criar produtos inovadores com vocação comercial e buscam na pesquisa das universidades os fundamentos do conhecimento para tal. Completando o modelo da tripla hélice, o governo deve articular, estimular e dar suporte às relações acima descritas, cumprindo um papel importante de catalisador.

No cenário nacional, a relação universidade-empresa se tornou mais estreita com a criação dos Núcleos de Inovação Tecnológica (NIT), através da Lei no 10.973/2004, (Lei de Inovação), por meio da obrigatoriedade das universidades e institutos públicos de pesquisa e tecnologia (Instituição de Ciência e Tecnologia - ICT) instituírem um órgão interno (NIT), com o papel de gerir suas

MELO, J. dos S. et al..Utilização de ferramentas de inteligência competitiva para delinear estratégias de posicionamento de mercado de equipamentos eletromédicos de monitoramento. 
políticas de inovação, que estimulou acentuadamente a transferência de tecnologias por parte da universidade (BRASIL, 2004).

O modelo da tripla hélice funciona como estimulador da inovação e do desenvolvimento econômico do país, por meio da relação de três esferas: universidade, empresa e governo. Para Mello et al. (2016), estas interações entre Universidade, Empresa e Governo, funcionam como base para as políticas de incentivo à inovação tecnológica de uma localidade, que segundo Kato (2008 apud MELLO et al., 2016), são responsáveis por estabelecer o pilar da sociedade contemporânea.

A transferência de tecnologia é importante no sentido de materializar a continuidade do processo de implementação de inovações, levando para o mercado um conhecimento novo, com relativa vantagem competitiva para o investidor e benefício para o usuário final (FERNANDES, 2003).

A formalização das parcerias universidade, empresa e governo, assim como a formalização da transferência de tecnologia pode se dar por meio dos contratos.

O contrato de transferência de tecnologia realizado entre o fornecedor e o receptor da tecnologia se configura de diferentes modos, como por exemplo, contrato de licenciamento de tecnologia e contrato de transferência de know-how.

No que tange a tecnologia estudada, o contrato de know-how é aconselhável como um instrumento complementar ao contrato de licenciamento da tecnologia, tendo em vista que a petição depositada do Instituto Nacional da Propriedade Industrial (INPI) não é suficientemente descritiva de forma a possibilitar que o licenciado consiga construir o dispositivo apenas por meio de sua leitura.

Um termo de cooperação técnica pode ser celebrado também com ambientes que possuam elevada estrutura de equipamentos médicos para a realização de testes de validação e melhoramento dessas tecnologias. Nesse arranjo, não há ganhos econômicos, mas a vantagem de testes de validação mais robustos que aqueles realizados em bancada. Por consequência dessa ação, as tecnologias passam a adquirir a facilidade nos quesitos de certificação, além da sua maior valoração antes mesmo da negociação de transferência para a empresa, ou seja, a figura dos ganhos econômicos existe de forma mediata.

No que tange o pagamento pelo licenciamento das tecnologias, sugere-se um percentual de $5 \%$ de royalties mínimos, de forma bruta, dispensando assim os cálculos de desconto que deveriam ser feitos no valor líquido, nos primeiros 2 anos, e de forma escalonada para os anos posteriores, com uma taxa inicial (Lump Sump). Essa sugestão teve como embasamento os estudos apresentados pelo o professor e consultor Russell L. Parr, que pelo estudo comprovou que a taxa de $5 \%$ é a mais utilizada para os pagamentos de royalties em equipamentos médicos (PARR, 2016).

Já a definição de royalty de forma escalonada, para os anos posteriores, foi estabelecida devido a essa modalidade estimular o aumento da comercialização da tecnologia pelo licenciado, sem prejudicar o valor absoluto que o licenciado recebe (QUINTELLA; TEODORO, 2013). Ela permite que o percentual de royalties varie de acordo com a demanda de ganhos, aumentando seu percentual quando os ganhos estiverem baixos e diminuindo quando estiverem altos, proporcionando ao fornecedor da tecnologia sempre um ganho médio independentemente da situação das vendas do produto. A utilização dessa modalidade a partir do terceiro ano possibilita uma renegociação da contrapartida econômica de maneira mais justa, pois nesse momento se terá indicadores reais do desempenho das tecnologias no mercado ao longo dos dois primeiros anos de comercialização.

\section{CONSIDERAÇÕES FINAIS}

Por meio da utilização das ferramentas de inteligência competitiva pôde-se analisar o

MELO, J. dos S. et al..Utilização de ferramentas de inteligência competitiva para delinear estratégias de posicionamento de mercado de equipamentos eletromédicos de monitoramento. 
posicionamento da tecnologia estudada no mercado e assim sugerir a modalidade para realização da transferência de tecnologia.

As prospecções também mostraram que existem artigos publicados sobre a temática, patentes depositadas e empresas que fabricam e comercializam equipamentos eletromédicos, porém com foco internacional, propiciando um mercado nacional menos competitivo para tecnologias nessa área e corroborando para uma maior valoração dos equipamentos.

No contexto atual, a ausência de depósitos de patentes brasileiras nesta área poderia ser relacionada ao fato da falta de incentivo e investimento à pesquisa e ao desenvolvimento de novas tecnologias. Ademais, observou-se também um baixo número de publicações científicas relacionadas ao tema, quando comparada com os Estados Unidos e outros países, mostrando a necessidade de mais estudos por parte dos pesquisadores brasileiros nesta área, ao passo que se torna um campo promissor para pesquisa, desenvolvimento de novas tecnologias e consequente modernização e otimização dos serviços de saúde. Outro motivo que pode impactar nos baixos índices patentários brasileiros está relacionado à dificuldade de classificar os equipamentos eletromédicos, como apontado pela Agência Brasileira de Desenvolvimento Industrial.

Com a matriz SWOT foi possível constatar que apesar de tecnologias de equipamentos serem nacionais, esse fato pode propiciar uma redução no custo das manutenções dos equipamentos hospitalares e podendo ir ao mercado com custo menor em relação a equipamentos semelhantes. De toda forma, as tecnologias ainda dependerão de alguns testes e deverão estar em constante atualização para que não se torne obsoleta.

Diante dos resultados apresentados foi possível observar que o mercado internacional de equipamentos eletromédicos de monitoramento está em expansão. Porém, no Brasil, apesar do incentivo do governo, o desenvolvimento de estudos e tecnologias deste tipo ainda é insipiente. Devido a esse déficit, a tecnologia se torna promissora no mercado, possibilitando um diálogo facilitado com os possíveis licenciadores no ato da transferência de tecnologia.

\section{REFERÊNCIAS}

AGÊNCIA BRASILEIRA DE DESENVOLVIMENTO INDUSTRIAL. Estudo prospectivo: equipamentos médicos, hospitalares e odontológicos. Brasília: ABDI, 2008a. (Série Cadernos da Indústria ABDI, v. 8). Disponível em: <http://www.abdi.com.br/Estudo/VIII.pdf>. Acesso em: 17 maio 2017.

AGÊNCIA BRASILEIRA DE DESENVOLVIMENTO INDUSTRIAL. Panorama setorial: equipamentos médicos, hospitalares e odontológicos. Brasília: ABDI, 2008b. (Série Cadernos da Indústria ABDI, v. 7). Disponível em: <http://www.abdi.com.br/Estudo/volume\%207.pdf>. Acesso em: 20 jun. 2017.

ASSOCIAÇÃO BRASILEIRA DA INDÚSTRIA DE ARTIGOS E EQUIPAMENTOS MÉDICOS, ODONTOLÓGICOS, HOSPITALARES E DE LABORATÓRIOS. Dados econômicos. São Paulo, 2017a. Disponível em: <https://abimo.org.br/dados-do-setor/dados-economicos/>. Acesso em: 29 jun. 2017.

ASSOCIAÇÃO BRASILEIRA DA INDÚSTRIA DE ARTIGOS E EQUIPAMENTOS MÉDICOS, ODONTOLÓGICOS, HOSPITALARES E DE LABORATÓRIOS. Dados de comércio exterior. São Paulo, 2017b. Disponível em: <https://abimo.org.br/dados-do-setor/dados-de-comercioexterior/>. Acesso em: 29 jun. 2017.

MELO, J. dos S. et al..Utilização de ferramentas de inteligência competitiva para delinear estratégias de posicionamento de mercado de equipamentos eletromédicos de monitoramento. 
ASSOCIAÇÃO BRASILEIRA DE NORMAS TÉCNICAS. NBR IEC 60601-1: equipamento eletromédico: parte 1: prescrições gerais para segurança. Rio de Janeiro, 1994.

ASSOCIAÇÃO BRASILEIRA DE NORMAS TÉCNICAS. NBR IEC 60601-1: equipamento eletromédico: parte 1: prescrições gerais para segurança: emenda 1. Rio de Janeiro, 1997.

BORSCHIVER, Suzana (Org.); SILVA, Andrezza Lemos Rangel da (Org.). Technology roadmap: planejamento estratégico para alinhar mercado-produto-tecnologia. Rio de Janeiro: Interciência, 2016.

BRASIL. Lei n. 10.973, de 02 de dezembro de 2004 . Disponível em: <http://www.planalto.gov.br/ccivil_03/_ato2004-2006/2004/lei/110.973.htm>. Acesso em: 22 jun. 2017.

CLOSS, Lisiane Quadrado; FERREIRA, Gabriela Cardozo Ferreira. A transferência de tecnologia universidade-empresa no contexto brasileiro: uma revisão de estudos científicos publicados entre os anos 2005 e 2009. Gestão \& Produção, São Carlos, v. 19, n. 2, p. 419-432, 2012. Disponível em: <http://www.scielo.br/pdf/gp/v19n2/v19n2a14.pdf >. Acesso em: 17 jun. 2017.

DIAS; Alexandre Aparecido; PORTO, Geciane Silveira. Gestão de Transferência de Tecnologia na Inova Unicamp. Revista de Administração Contemporânea, Rio de Janeiro, v. 12, n. 3, p. 263284, maio/jun. 2013. Disponível em: <http://www.scielo.br/scielo.php?script=sci_arttext\&pid=S1415-65552013000300002〉. Acesso em: 17 jun. 2017.

DISTRITO FEDERAL. Secretaria de Estado de Saúde. Relatório anual de gestão: 2015. Brasília: SESDF, 2015.2 Disponível em: <http://www.saude.df.gov.br/images/LAI/planejamento/2016/RAG_2015_SESDF.pdf>. Acesso em: 04 jun. 2017.

DISTRITO FEDERAL. Tribunal de contas do Distrito Federal. Nos hospitais do DF, 80\% dos equipamentos de UTI não têm manutenção adequada. Brasília, 2017. Disponível em: <http://www.tc.df.gov.br/web/tcdf1/noticias/-/asset_publisher/E2Ot/content/nos-hospitais-do-df-80dos-equipamentos-de-uti-nao-tem-manutencao-

adequada?redirect=\%2Fweb\%2Ftcdf1\%2Fnoticias $>$. Acesso em: 04 jun. 2017.

FERNANDES, J. Gestão da tecnologia como parte da estratégia competitiva das empresas. Brasília: IPDE, 2003.

FERNANDES, R. Tecnologia: aquisição, desenvolvimento, proteção, transferência e comercialização. Rio de Janeiro: Quadratim, 1998.

GOMES, Elisabeth; BRAGA, Fabiane. Construção de um sistema de inteligência competitiva. In: STAREC, Cláudio; GOMES, Elisabeth; BEZERRA, Jorge. Gestão estratégica da informação e inteligência competitiva. 1. ed., 5. tir. São Paulo: Saraiva, 2011. p. 111-123.

MELLO, J. A. V. B. et al. Percepções e avaliação do setor empresarial a respeito de possibilidades de tríplice hélice com uma IFES interiorizada. HOLOS, ano 32, v. 1, p. 215-230, fev. 2016. Disponível em: <http://www2.ifrn.edu.br/ojs/index.php/HOLOS/article/view/2483/1385>. Acesso em: 26 jun. 2017.

MELO, J. dos S. et al..Utilização de ferramentas de inteligência competitiva para delinear estratégias de posicionamento de mercado de equipamentos eletromédicos de monitoramento. 
NASCIMENTO, M. A; TANAKA, H. Mapeamento do custo de manutenção de equipamentos médicos no estado de São Paulo. In: CONGRESSO BRASILEIRO DE ENGENHARIA BIOMÉDICA, 24., 2014, Uberlândia-MG. Anais... Uberlândia: UFU, 2014. p. 701-704. Disponível em: 〈http://www.canal6.com.br/cbeb/2014/artigos/cbeb2014_submission_213.pdf〉. Acesso em: 18 maio 2017.

NASCIMENTO, Paulo Gustavo Barboni Dantas. Aula 02: maturidade tecnológica. Brasília, 2017. [Slides da disciplina de Prospecção Tecnológica do Mestrado Profissional de Propriedade Intelectual e Transferência de Tecnologia para Inovação]. Disponível em: <https://aprender.ead.unb.br/pluginfile.php/331572/mod_resource/content/1/aula2.pdf>. Acesso em: 04 jun. 2017.

PARR, Russel L. Royalty rates for medical devices \& diagnostics. Pennsylvania: IPAR, 2016. Available at: <http://techtransfercentral.com/wp-content/uploads/2010/01/Royalty-Rates-forMedical-Devices-and-Diagnostics-2016-Edition-TOC.pdf>. Accessed in: 22 June 2017.

QUINTELLA, Cristina M.; TEODORO, Auristela Felix de Oliveira. Os ganhos econômicos diante da propriedade intelectual: retorno do investimento à sociedade. In: SIMPÓSIO DE EXCELÊNCIA EM GESTÃO E TECNOLOGIA, 10., 2013, Rio de Janeiro. Anais... Rio de Janeiro: AEDB, 2013. Disponível em: <http://www.aedb.br/seget/arquivos/artigos13/35018338.pdf>. Acesso em: 19 jun. 2017.

SEBRAE. O que é inteligência competitiva, 2017c. Disponível em: $<$ https://www.sebrae.com.br/sites/PortalSebrae/artigos/o-que-e-inteligenciacompetitiva,a41d6d461ed47510VgnVCM1000004c00210aRCRD>. Acesso em: 18 jun. 2017.

XAVIER, Guilherme. Quebrou, chamou, pagou: custos de manutenção de equipamentos médicos. Healthcare Management, 23 out. 2015. Disponível em: <http://healthcaremanagement.grupomidia.com/custos-manutencao-equipamentos-medicos/>. Acesso em: 30 maio 2017. 